\title{
Anatomia descritiva da traqueia do macaco-prego (Sapajus apella)
}

\author{
Luciano César Pereira Campos Leonel * \\ Tânia Cristina Lima \\ Rodrigo Lopes de Felipe \\ Elaine Maria da Silva \\ Gustavo Alexandre de Oliveira Silva \\ Daniela Cristina de Oliveira Silva \\ Roseâmely Angélica de Carvalho-Barros \\ Zenon Silva \\ Universidade Federal de Goiás \\ Avenida Margon, 890, Margon II, CEP 75711-020, Catalão - GO, Brasil \\ * Autor para correspondência \\ enf.luciano@yahoo.com.br
}

Submetido em 28/06/2013

Aceito para publicação em 16/07/2013

\section{Resumo}

O estudo descritivo da anatomia de animais silvestres experimenta, nos dias atuais, inegável importância. O cerrado constitui um bioma complexo que abriga uma grande variedade de espécies, entre elas, o macaco-prego (Sapajus apella); foram utilizados quatro espécimes, comparando os resultados encontrados com a literatura humana e veterinária, já bem estabelecidas. Os espécimes foram fixados em solução aquosa de formol a 10\%, dissecados, analisados descritivamente e fotografados. Os resultados evidenciam uma traqueia cuja extensão varia conforme a compleição física do animal, um número variável de anéis cartilaginosos incompletos, sendo o fechamento do tubo, na face dorsal, feito por tecido musculomembranoso. A parede musculomembranosa não é uniforme em toda a sua extensão, exibindo maior largura no terço médio-cranial. Então, a traqueia do $S$. apella não diverge muito daquela observada no homem e animais domésticos, sendo as variações, aparentemente, relacionadas às adaptações à compleição física do animal.

Palavras-chave: Anatomia; Anatomia comparada; Anatomia veterinária; Traqueia

\section{Abstract}

Descriptive anatomy of trachea in the tufted capuchin monkey (Sapajus apella). The descriptive study of wild animals' anatomy enjoys an undeniable importance nowadays. Cerrado constitutes a complex biome which is home to a wide variety of species, among them the tufted capuchin monkey (Sapajus apella); four specimens were used, comparing the results found to the human and veterinary literature, which are already wellestablished. The specimens were fixed in a $10 \%$ formalin aqueous solution, dissected, analyzed in a descriptive 
way, and photographed. The results show a trachea whose length varies according to the animal's physique, a variable number of incomplete cartilage rings, and the tube closure, in the dorsal face, occurs by means of musculomembranous tissue. The musculomembranous wall isn't uniform throughout its length, showing the greatest width at the middle cranial third. So, the trachea in S. apella doesn't differ much from that observed in the human being and domestic animals, and the variations are, seemingly, related to adaptations to the animal's physique.

Key words: Anatomy; Comparative anatomy; Trachea; Veterinary anatomy

\section{Introdução}

O estudo comparativo-descritivo da anatomia de animais silvestres está em fase de franco crescimento, no Brasil, e em outras partes do mundo, principalmente agora quando o bioma natural de muitos grupos sofre múltiplas agressões, obrigando muitas espécies a migrarem em busca de maior segurança alimentar, reprodutiva e porque não, de sua própria sobrevivência, ou então, engrossando cada vez mais o rol das espécies em risco ou em processo de extinção.

O Sapajus apella é um primata de médio porte, cuja massa corporal varia até 5-6 kg, apresenta larga distribuição ao longo da América Central e do Sul e é bastante versátil, vivendo em matas, Caatinga e, principalmente, áreas de restingas e cerrados. É um primata que se adapta com razoável facilidade, inclusive se reproduzindo em cativeiro sem maiores problemas. Muito embora possa ser considerado, talvez o primata não humano mais inteligente do novo mundo, ainda é quase desconhecido, no que se refere à sua Anatomia.

Por outro lado, há tempos vivenciamos situações de conflito entre o homem e a natureza, mesmo quando se tenta educar a sociedade no sentido de utilizar os recursos naturais de forma sustentável. Para Benite e Mamede (2008), a proposta de educação ambiental representa uma forma de interação entre ciências, e a mesma tornase indispensável nas novas políticas de uma sociedade sustentável, gerando muito mais que preocupações, mas também a sensibilização e direcionamento nas tomadas de decisões para estratégias de conservação.

É fato que a exploração indiscriminada da fauna e da flora brasileira tem, ao longo dos tempos, produzido sérias consequências, não apenas para o meio ambiente natural, mas também para o Homem que usufrui dele. Já é comprovada a extinção tanto de espécies exclusivas do território nacional, já cientificamente, bem conhecidas, como de espécies que sequer foram estudadas.

Assim sendo, face à conjuntura atual, a comunidade científica vem se preocupando cada vez mais, em estudar e desenvolver trabalhos que possam contribuir com a melhoria do conhecimento, assim como fornecer subsídios para a preservação de espécies ameaçadas. As variantes como biologia comportamental, fisiologia e morfologia comparativa são instrumentos de grande importância nessa nova abordagem de conhecimento (MOURA et al., 2012).

O Cerrado é um bioma complexo, que abriga uma grande variedade de espécies, incluindo muitos mamíferos em risco de extinção. Não obstante há espécies que adotaram o cerrado como lar, depois que tiveram seus habitats alterados ou destruídos, principalmente, por ação humana. Segundo Aguiar e Camargo (2004), este bioma corresponde à aproximadamente $21 \%$ do território nacional, com uma área de 1,8 milhões de $\mathrm{km}^{2}$, porém ao longo dos anos, com sua intensa exploração e destruição acredita-se que nos tenha restado apenas 43\% de sua área original (MEDEIROS, 2012).

Um dos fatores que explica a perda de áreas do cerrado é, principalmente, a disponibilidade de partes que ainda não foram exploradas comercialmente, uma vez que houve o esgotamento das áreas cultiváveis na porção central e sul do bioma, além deste bioma oferecer condições físicas que permitem o avanço da pastagem e demais culturas agrícolas (BOCCHIGLIERI et al., 2010).

Conhecer a biologia de animais do cerrado, entre eles o Sapajus apella, faz parte das contribuições que norteiam a organização e implantação de programas de proteção e preservação. O sistema respiratório do 
macaco-prego ( $S$. apella) mostra importância sob os aspectos anatômicos, fisiológicos e evolutivos, sendo o enfoque desta pesquisa comparar a Anatomia da traqueia do macaco-prego (S. apella) com a do homem, vez que ambos os grupos são primatas, porém filogeneticamente em posições diferentes, embora próximas e a Anatomia do Homem já se encontra bem estabelecida.

\section{Material e Métodos}

A presente pesquisa foi aprovada pelo Comitê de Ética em Pesquisa da Universidade Federal de Goiás com o número do protocolo 045/12. Neste estudo foram utilizados quatro espécimes de macaco-prego (S. apella). A amostra, composta por três machos e uma fêmea foi doada pelo IBAMA - MG, após óbito por causas variadas. Cada espécime foi fixado com solução aquosa de formol a $10 \%$ e nela conservado até o processamento (dissecação) para análise. Depois de fixados, os animais foram dissecados e analisados à luz de técnicas usuais em Anatomia Macroscópica.

\section{Resultados}

Com base nas dissecações verifica-se que a traqueia do $S$. apella é um tubo aerífero cilíndrico, porém, um pouco achatado dorso-ventralmente que se estende desde a borda caudal da cartilagem cricóide (Figura 1a; 2a) até a origem dos brônquios principais esquerdo e direito. A traqueia deste animal é constituída por 29 a 30 anéis cartilaginosos incompletos (Figura 1d), os quais na porção dorsal são formados, não por cartilagem, mas por uma parede musculomembranosa, o 'músculo traqueal' (Figura 2b). A largura desta parede não é uniforme em toda a extensão da traqueia, mostrando-se mais larga no terço médio-cranial.

Alguns dos anéis componentes da traqueia são ramificados (Figura 1e) e outros não. Na porção caudal o músculo traqueal é muito estreito, porque as extremidades dos anéis tendem a ser muito próximas, porém, não se unem. Na extremidade cranial a traqueia está conectada à cartilagem cricóide, por meio da membrana cricotraqueal e cada um dos anéis cartilaginosos da traqueia unem-se aos outros por meio do ligamento anular (Figura 1c). Em sua extremidade caudal a traqueia divide-se em dois ramos: o Brônquio Principal Esquerdo (Figura 1f) e Brônquio Principal Direito (Figura 1g).

FIGURA 1: Fotomacrografia da traqueia do macaco-prego (Sapajus apella). Vista ventral: a-borda caudal da cartilagem cricóidea; b anel traqueal; c - ligamentos anulares; $\mathrm{d}$ - anéis incompletos, e - anel bifurcado, $\mathrm{f}$ - brônquio principal esquerdo, $\mathrm{g}$ - brônquio principal direito, $(-20 \%: 11,5 \mathrm{~cm})$.

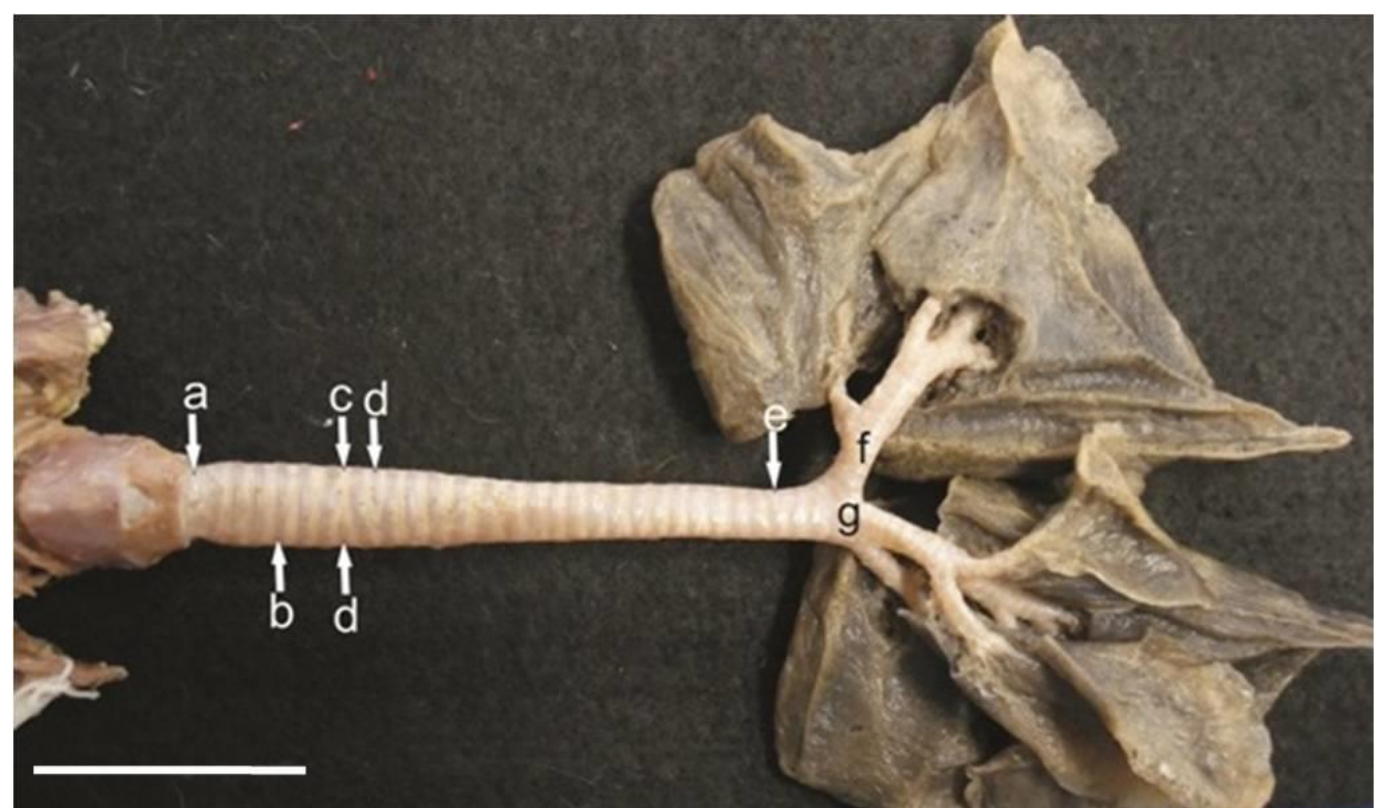


FIGURA 2: Fotomacrografia da traqueia do macaco-prego (Sapajus apella). Vista dorsal: a - cartilagem cricóidea; b - músculo traqueal, c - bifurcação em brônquios principais, $(-20 \%: 17,3 \mathrm{~cm})$.

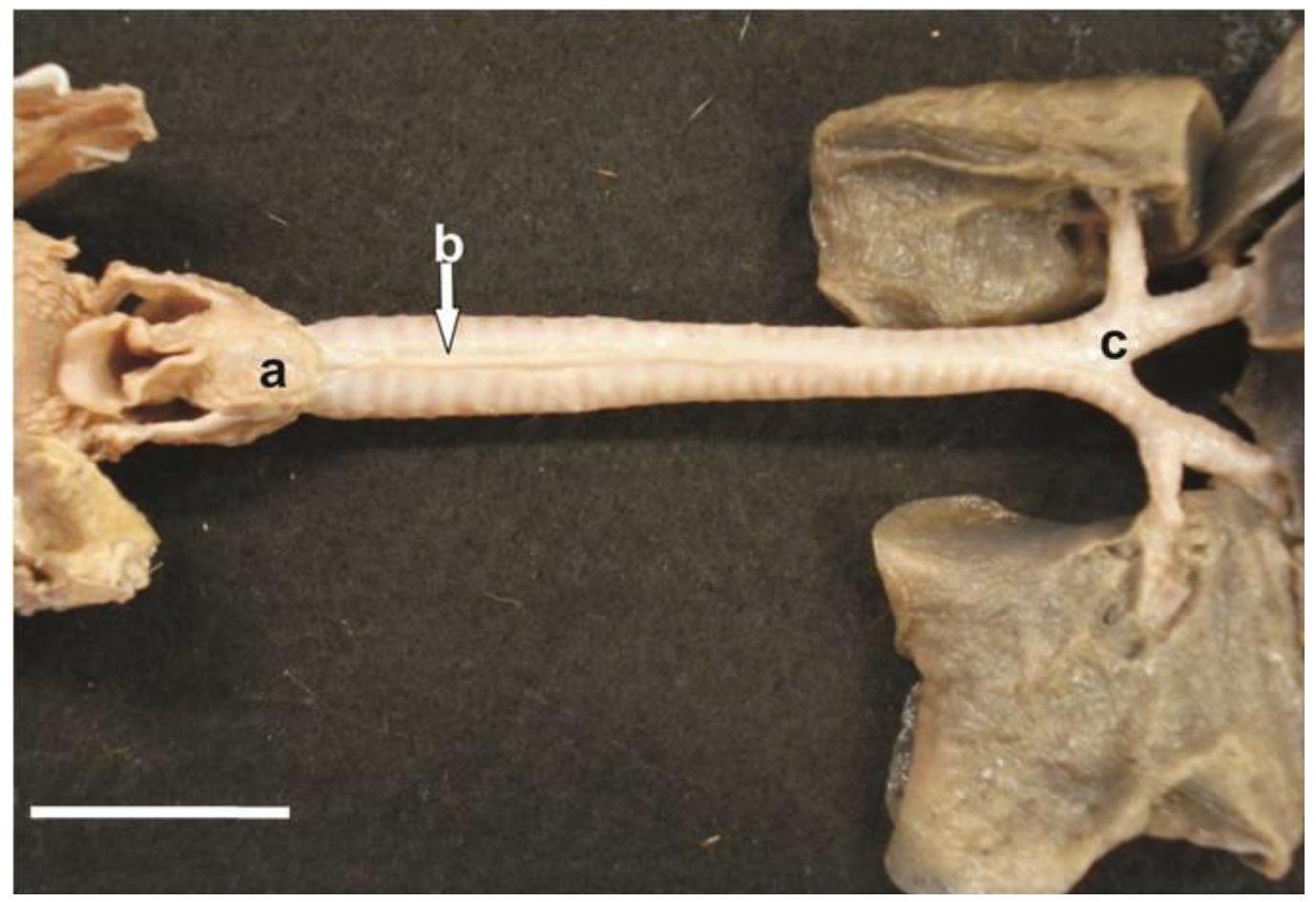

\section{Discussão}

Uma análise acurada das peças anatômicas utilizadas nesta pesquisa revela que a traqueia do macaco-prego é um tubo aproximadamente cilíndrico, levemente achatado dorso-ventralmente, que se estende desde a borda distal de cartilagem cricóide até o interior do tórax, findando em uma bifurcação que dá origem aos brônquios primários direito e esquerdo. Esses achados estão de acordo com as observações dos estudos de Testut e Latarjet (1979), em humanos, e Hare (2008), em carnívoros domésticos.

No $S$. apella, a traqueia ocupa posição mediana, ventralmente ao esôfago e dorsalmente aos músculos ventrais do pescoço por, aproximadamente, toda a sua extensão, mas nos segmentos caudais está um pouco deslocada para a direita, empurrada pela aorta. Esses resultados não concordam com as citações de Raven (1950), quando descreve a traqueia do gorila, no qual a mesma é deslocada à esquerda do esôfago ao nível de T1 e à direita no mediastino superior. Enquanto isso, a traqueia encontra-se posicionada no plano sagital, em
Lorisoidae, nos quais é constituída por anéis em formato de 'C' (HILL, 1955). Semelhante descrição é feita em humanos (TESTUT; LATARJET, 1979), e em animais domésticos (HARE, 2008). A traqueia do macaco-prego, conforme observações verificadas neste trabalho está constituída por anéis cartilaginosos incompletos, cujo número varia entre 29 a 30, mas esse número não está relacionado ao comprimento do pescoço, tão pouco está associado ao porte do animal. O formato em ' $\mathrm{C}$ ' descrito por Testut e Latarjet (1979), em humanos e por Hill (1955) em Lorisoidea não foi observado no S. apella, vez que as extremidades livres dos semianéis encontram-se muito próximas uma da outra, por vezes exibindo apenas um filete de membrana. A literatura compulsada neste artigo indica consideráveis divergências nesse aspecto, no gorila há descrições de 17 anéis (RAVEN, 1950). Já o gênero Aloautta exibe 14 a 15 anéis, Brachyteles e Lagothrix, 22 anéis e Ateles 25 anéis (HILL, 1962).

A literatura descreve a traqueia humana com um número aproximado de 15 a 20 anéis (TESTUT; LATARJET, 1979), igualmente, em outros táxons ocorre 
grande variação quanto ao número dos mesmos. Assim, no cão doméstico há 42 a 46 anéis; 38 a 48 no gato, 32 a 36 em suínos, 48 a 60 em equinos e ruminantes (HARE, 2008). No Saimiri sciureus, segundo Pinheiro et al. (2012), o número de anéis varia entre 30 e 36 nos animais jovens e 28 a 32 nos adultos. A grande variabilidade relativa ao número de anéis traqueais nos diferentes grupos sugere a ausência de associação entre o número de anéis, quer seja inter ou intra-específica. Além disso, animais com pescoço mais curto podem exibir um número maior de anéis e vice-versa.

Por outro lado, a largura dos anéis é igualmente um aspecto variável na espécie estudada, alguns podem ser ramificados e anastomoses podem ocorrer entre os ramos. Os resultados desta pesquisa corroboram com a descrição encontrada na literatura de Raven (1950), em gorila, de Testut e Latarjet (1979), em humanos e a de Hare (2008), em animais domésticos.

No gorila foram descritas duas placas bifurcadas (RAVEN, 1950), ocorre ainda bifurcação em Lorisoidea e Pithecoidea, alguns anéis são bifurcados e a sua descontinuidade é maior cranialmente em relação aos segmentos caudais (HILL, 1955). Em Hapalideos alguns anéis são bifurcados (HILL, 1957). A largura e o número de anéis ao longo de toda a extensão da traqueia variam consideravelmente de espécie para espécie (TESTUT; LATARJET, 1979; HARE, 2008), mas nossas observações em macaco-prego sugerem variabilidade inclusive intra-específica.

A estrutura anatômica da traqueia do $S$. apella não apresenta grandes divergências em relação à morfologia da traqueia de humanos e de animais domésticos.

\section{Referências}

AGUIAR, L. M. S.; CAMARGO, R. B.; MARINHO-FILHO, J. A diversidade biológica do Cerrado. In: AGUIAR, L. M. S.; CAMARGO, A. J. A. (Ed.). Cerrado: ecologia e caracterização. Planaltina: Embrapa Cerrados; Brasília. 2004. p. 17-40.

BENITES, M.; MAMEDE, S. B. Mamíferos e aves como instrumentos de educação e conservação ambiental em corredores de biodiversidade do Cerrado, Brasil. Mastozoologia Neotropical, Mendoza, v. 15, n. 2, p. 261-271, 2008.

BOCCHIGLIERI, A.; MENDONÇA, A. F.; HENRIQUES, R. P. B. Composição e diversidade de mamíferos de médio e grande porte no Cerrado do Brasil central. Biota Neotropical, Campinas, v. 10, n. 3, p. 169-176, 2010.

HARE, W. C. D. Sistema respiratório do carnívoro. In: GETTY, R. (Ed.). Sisson \& Grossman: anatomia dos animais domésticos. Vol. 2. 5. ed. Rio de Janeiro: Guanabara Koogan, 2008. p. 1465-1480.

HILL, W. C. O. Primates comparative anatomy and taxonomy II Haplorhini: Tarsioidea. Edinburgh: University Press, 1955. 189 p.

HILL, W. C. O. Primates comparative anatomy and taxonomy $\mathbf{V}$ Cebidae. Edinburgh: University Press, 1962. 414 p.

HILL, W. C. O. Primates comparative anatomy and taxonomy III Pithecoidea Platyrrhini. Edinburgh: University Press, 1957. $165 \mathrm{p}$.

MEDEIROS, K. M. O planejamento ambiental e exploratório no bioma do Cerrado. Revista Facitec, Taguatinga, v. 1, n. 1, s/ paginação, 2007.

MOURA, C. E. B.; ALBUQUERQUE, J. F. G.; MAGALHÃES, M. S.; SILVA, N. B.; OLIVEIRA, M. F.; PAPA, P. C. Análise comparativa da origem do plexo braquil de catetos (Tayassu tajacu). Pesquisa Veterinária Brasileira, Brasília, v. 27, n. 09, p. 357-362, 2007.

PINHEIRO, L. L.; LIMA, A. R.; MUNIZ, J. A. P. C.; IMBELONI, A.; FIORETO, E. T.; FONTES, R. F.; CABRAL, R.; BRANCO, E. Anatomy and morphometric aspects of the trachea of Saimiri sciureus Linnaues, 1758: knowledge for emergency procedures. Anais da Academia Brasileira de Ciências, Rio de Janeiro, v. 84, n. 4, p. 973-977, 2012.

RAVEN, H. C. The Anatomy of the Gorilla. New York: Columbia University Press, 1950. 190 p.

TESTUT, L.; LATARJET, A. Aparato de la repiracion y de la fonacion. In: TESTUT, L.; LATARJET, A. (Ed.). Tratado de anatomia humana. São Paulo: Ed. Salvat, 1979. p. 881-1021. 